Check for updates

Cite this: Chem. Sci., 2019, 10, 5712

๑ All publication charges for this article have been paid for by the Royal Society of Chemistry

Received 29th March 2019

Accepted 3rd May 2019

DOI: $10.1039 / \mathrm{c} 9 \mathrm{sc01539f}$

rsc.li/chemical-science

\section{Acid-durable electride with layered ruthenium for ammonia synthesis: boosting the activity via selective etching $\dagger$}

\author{
Jiang Li, (D) $\ddagger^{a}$ Jiazhen Wu, (D) $\ddagger^{a}$ Haiyun Wang, (DD ${ }^{b}$ Yangfan Lu, (D) ${ }^{a}$ Tiannan Ye, (D) ${ }^{a}$

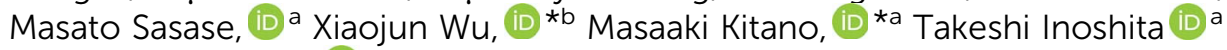 \\ and Hideo Hosono (D)*a
}

Ruthenium ( $\mathrm{Ru}$ ) loaded catalysts are of significant interest for ammonia synthesis under mild reaction conditions. The $\mathrm{B}_{5}$ sites have been reported as the active sites for ammonia formation, i.e., Ru with other coordinations were inactive, which has limited the utilization efficiency of Ru metal. The implantation of $\mathrm{Ru}$ into intermetallic compounds is considered to be a promising approach to tune the catalytic activity and utilization efficiency of Ru. Here we report an acid-durable electride, $\operatorname{LnRuSi}(\mathrm{Ln}=\mathrm{La}, \mathrm{Ce}, \operatorname{Pr}$ and $\mathrm{Nd}$ ), as a $\mathrm{B}_{5}$-site-free Ru catalyst. The active Ru plane with a negative charge is selectively exposed by chemical etching using disodium dihydrogen ethylenediaminetetraacetate (EDTA-2Na) acid, which leads to 2-4-fold enhancement in the ammonia formation rate compared with that of the original catalyst. The turnover frequency (TOF) of LnRuSi is estimated to be approximately $0.06 \mathrm{~s}^{-1}$, which is 600 times higher than that of pure Ru powder. Density functional theory (DFT) calculations revealed that the dissociation of $\mathrm{N}_{2}$ occurs easily on the exposed Ru plane of LaRuSi. This systematic study provides firm evidence that layered Ru with a negative charge in LnRuSi is a new type of active site that differs significantly from $B_{5}$ sites.

\section{Introduction}

Ammonia synthesis is one of the most important processes in industry. Ruthenium catalysts are of particular interest for ammonia synthesis and have been widely investigated as they function under mild conditions and exhibit a tenfold increase in the rate of ammonia synthesis compared with the conventional promoted iron catalyst. ${ }^{\mathbf{1 - 4}}$ The energy barrier for $\mathrm{N}_{2}$ dissociation has been decreased with promotion by alkali/alkali earth metal oxides, which have electron donating ability, and this has led to significant enhancements in ammonia formation rates. ${ }^{5-8}$ Therefore, a support or promoter with stronger electron donation ability may further enhance the activity of $\mathrm{Ru}$ catalysts. This has been achieved using electride materials such as C12A7: $\mathrm{e}^{-}$and $\mathrm{Y}_{5} \mathrm{Si}_{3}: \mathrm{e}^{-},{ }^{-13}$ where the electrons are localized in

\footnotetext{
${ }^{a}$ Materials Research Center for Element Strategy, Tokyo Institute of Technology, 4259 Nagatsuta, Midori-ku, Yokohama 226-8503, Japan. E-mail: kitano.m.aa@m.titech.ac. jp; hosono@msl.titech.ac.jp

${ }^{b}$ Hefei National Laboratory for Physical Sciences at the Microscale, Synergetic Innovation of Quantum Information \& Quantum Technology, School of Chemistry and Materials Science, CAS Key Laboratory of Materials for Energy Conversion, CAS Center for Excellence in Nanoscience, University of Science and Technology of China, Hefei, Anhui 230026, P. R. China.E-mail: xjwu@ustc.edu.cn

† Electronic supplementary information (ESI) available. See DOI: 10.1039/c9sc01539f

\$ These authors contributed equally.
}

the cages/cavities as anions and can migrate onto the supported $\mathrm{Ru}$ to decrease the $\mathrm{N}_{2}$ dissociation barrier. For instance, the activation energy of $\mathrm{Ru} / \mathrm{C} 12 \mathrm{~A} 7: \mathrm{e}^{-}$for ammonia synthesis is $49 \mathrm{~kJ} \mathrm{~mol}^{-1}$, which is much lower than that of the conventional $\mathrm{Ru}-\mathrm{Cs} / \mathrm{MgO}$ catalyst $\left(120 \mathrm{~kJ} \mathrm{~mol}^{-1}\right)$, and the turnover frequency (TOF; $0.2 \mathrm{~s}^{-1}$ ) is one order of magnitude higher than that of the $\mathrm{Ru}-\mathrm{Cs} / \mathrm{MgO}$ catalyst $\left(0.008 \mathrm{~s}^{-1}\right) \cdot{ }^{\mathbf{9}, \mathbf{1 4}}$ The anionic electron in electride easily traps dissociated $\mathrm{H}$ atoms at the same site to form hydride ions $\left(\mathrm{H}^{-}\right)$with the reversible reaction of $\mathrm{e}^{-}+\mathrm{H} \leftrightarrow$ $\mathrm{H}^{-}$, which suppresses hydrogen poisoning of the $\mathrm{Ru}$ surfaces that always occurs with conventional Ru based catalysts. ${ }^{14}$

However, various investigations reveal that the active sites of $\mathrm{Ru}$ particles consist of five $\mathrm{Ru}$ atoms exposing a threefold hollow hexagonal close-packed (hcp) site and a bridge site close together, i.e., a $\mathrm{B}_{5}$-type site, where part of the atoms are edge/ step atoms. ${ }^{15-18}$ Both experimental results and theoretical calculations have shown that the barrier for $\mathrm{N}_{2}$ dissociation at a step site ( $\mathrm{B}_{5}$ site) of a $\mathrm{Ru}(0001)$ face is approximately $0.4 \mathrm{eV}$, which is much lower than that at a terrace site (ca. 1.8-1.9 $\mathrm{eV}) .{ }^{18-20}$ Thus, the dissociation rate of $\mathrm{N}_{2}$ at steps is at least 9 orders of magnitude higher than that on the terraces at $500 \mathrm{~K}$. The number of $\mathrm{B}_{5}$ sites is sensitive to the particle size; the optimized $\mathrm{Ru}$ particle size for ammonia synthesis is in the range of 1.8-3.5 nm. ${ }^{15-17}$ As a result, the fraction of $\mathrm{B}_{5}$ sites in total $\mathrm{Ru}$ atoms is rather small, which indicates that most $\mathrm{Ru}$ atoms are not active and are unused for the ammonia synthesis. $\mathrm{A}_{5}$-site- 
independent $\mathrm{Ru}$ catalyst is thus desirable to improve the utilization rate of $\mathrm{Ru}$.

Transition-metal (TM)-containing intermetallic compounds are promising candidates to realize high activity and high utilization of active TMs for various heterogeneous reactions, including ammonia synthesis. ${ }^{21-25}$ With active TM atoms implanted into the lattice of an intermetallic compound, both the geometric configuration and charge state of TM atoms are modified via the crystal structure and chemical bonding effects, and the stability of the catalyst would be improved by preventing the aggregation of active sites. For instance, intermetallic LaCoSi with negatively charged Co has shown good activity and stability for ammonia synthesis. ${ }^{21} \mathrm{Ru}$ exhibits higher activity for ammonia synthesis than Co, which suggests that Ru-containing intermetallics may also exhibit higher activity than LaCoSi, which was confirmed by the LaRuSi electride and $\mathrm{YRu}_{2}$ catalyst. ${ }^{26,27}$ These studies are strongly indicative of the possibility to realize active $\mathrm{Ru}$ sites other than $\mathrm{B}_{5}$ sites through the use of intermetallics. Following this suggestion, not only is the space for the exploration of new active catalysts expanded, but the approaches to improve catalytic activity will also be enriched.

Herein, we propose LnRuSi with layered $\mathrm{Ru}$ as a new type catalyst that differs from conventional Ru catalysts with $\mathrm{B}_{5}$ sites as active centers for ammonia synthesis. These intermetallic electrides are robust in terms of stability, even against some acids such as $\mathrm{HNO}_{3}$ and EDTA, in contrast to conventional electrides, which are unstable in the presence of air and moisture. ${ }^{28-30}$ According to the acid durability of these electrides, we have developed a simple selective etching method using EDTA$2 \mathrm{Na}$ solution to remove surface $\mathrm{Ln}$ and $\mathrm{Si}$, which enables the exposure rate of active $\mathrm{Ru}$ sites to be enhanced. The catalytic activity of etched LnRuSi toward ammonia synthesis is enhanced 2- to 4-fold compared with that of the original sample.

\section{Results and discussion}

LnRuSi electrides crystallize in a tetragonal structure with the space group $P 4 / \mathrm{nmm}$ (Fig. 1a), where Ru and Si layers are separated and sandwiched by double layers of $\mathrm{Ln}$. The Ln layers are composed of edge-shared $\mathrm{Ln}_{4}$ tetrahedra with a vacant space ( $\mathrm{V}$ site) located at the center (depicted as light blue balls in Fig. 1a) that can accommodate an electron or hydrogen anion. ${ }^{27}$
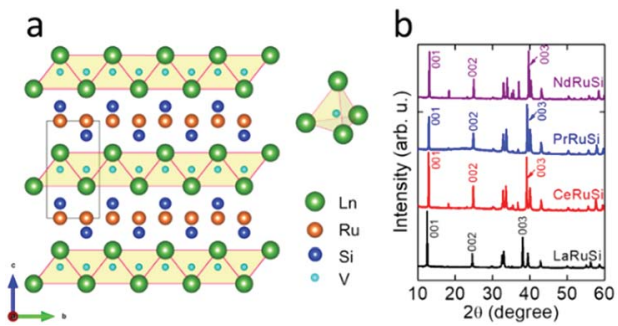

Fig. 1 (a) Crystal structure and (b) XRD patterns of $\operatorname{LnRuSi}(\mathrm{Ln}=\mathrm{La}, \mathrm{Ce}$, $\operatorname{Pr}$ and $\mathrm{Nd}$ ). The gray square shows the unit cell of LnRuSi, while the light blue spheres in the $\mathrm{Ln}_{4}$ tetrahedra represent the vacant spaces for electrons or hydrogen anions.
The crystal quality of LnRuSi was confirmed by Rietveld refinements of the obtained powder XRD data (Fig. $1 \mathrm{~b}$ and $\mathrm{S} 1 \dagger$ ). The 111 target phases with purity higher than $95 \mathrm{wt} \%$ were obtained for LaRuSi, CeRuSi and PrRuSi samples; however, the purity of NdRuSi was only as high as $83.5 \mathrm{wt} \%$, and the 122 impurity phase was difficult to remove completely, even after long-time annealing. It is noteworthy that the XRD patterns show that the (00l)-orientation is favored for all ground LnRuSi powders, which indicates that the exposed surfaces of the present catalysts are dominated by $(00 l)-\mathrm{Ln} / \mathrm{Ru} / \mathrm{Si}$ layers. This was confirmed by SEM measurements, as shown in Fig. S2, $\dagger$ where clear layered structures were observed for all LnRuSi compounds. The cleavage energy between different layers along the $z$ direction was calculated for LaRuSi using DFT to determine the most possible exposed surface. As shown in Fig. S3, $\dagger$ the cleavage energy between La-La layers $\left(0.051 \mathrm{eV} \AA^{-1}\right)$ was much lower than that between La-Si layers $\left(0.211 \mathrm{eV}^{-1}\right)$ and $\mathrm{Ru}-\mathrm{Si}$ layers $\left(0.312 \mathrm{eV} \AA^{-1}\right)$. Therefore, cleavage between the LaLa layers is most likely to occur during the milling process, i.e., $(00 l)$-La terminated surfaces should be the major exposed surfaces for the hand-milled powder of LaRuSi, and accordingly, for other LnRuSi compounds.

The catalytic performance for ammonia synthesis over the LnRuSi electride catalysts is shown in Fig. 2 and summarized in Table S2. $\uparrow$ The LnRuSi catalysts exhibited much higher activity than pure Ru powder with a similar surface area (as high as 3080 times), and were comparable to conventional iron or ruthenium based catalysts. For instance, the ammonia yield over LaRuSi was $0.492 \%$, which was much higher than that over commercial $\mathrm{Fe}-\mathrm{K}_{2} \mathrm{O}-\mathrm{Al}_{2} \mathrm{O}_{3}(0.164 \%)$ under same operation condition..$^{31}$ On the other hand, no ammonia formation was observed over the Ru-free compounds, including the LaScSi electride, $\mathrm{LaSi}$ and $\mathrm{La}_{5} \mathrm{Si}_{3}$ (Table $\mathrm{S} 3 \uparrow$ ), which indicates that lattice $\mathrm{Ru}$ atoms in LaRuSi are the active sites for ammonia synthesis.

Moreover, present LnRuSi electrides are robust to air and water. The ammonia synthesis over LaRuSi catalysts that were

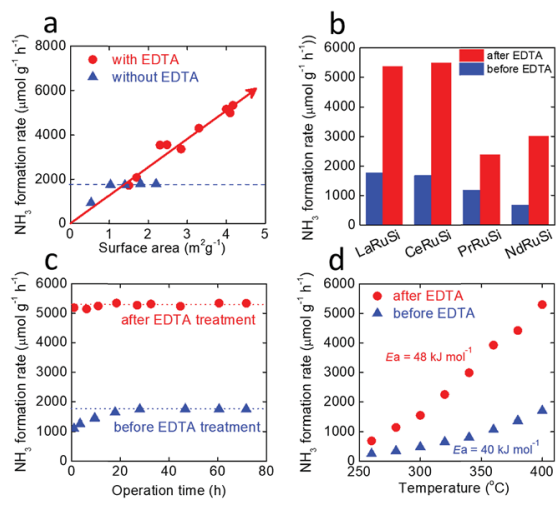

Fig. 2 Catalytic performance for ammonia synthesis over LnRuSi catalysts before and after EDTA treatment. (a) Effect of surface area on activity for $\mathrm{NH}_{3}$ formation over LaRuSi, (b) activity over LnRuSi, and (c) stability, and (d) effect of temperature for LaRuSi. The catalytic activities were measured for $0.1 \mathrm{~g}$ of catalyst at $0.1 \mathrm{MPa}$ with $\mathrm{H}_{2} / \mathrm{N}_{2}=45 / 15$ $\mathrm{mL} \min ^{-1}$ flow, observed temperature for $(\mathrm{a}-\mathrm{c})$ was $400{ }^{\circ} \mathrm{C}$. 
stored in air for half year and treated with water for $24 \mathrm{~h}$. The ammonia formation rate for these samples were 1800 and 1760 $\mu \mathrm{mol} \mathrm{g}_{\text {cat }}{ }^{-1} \mathrm{~h}^{-1}$, respectively, almost identical to that for the as prepared catalyst of $1810 \mu \mathrm{mol} \mathrm{g}$ cat $^{-1} \mathrm{~h}^{-1}$ (Table S4 $\dagger$ ). The XRD measurements were performed for these samples, and we did not find any clear phase change (Fig. S4 $\dagger$ ). Moreover, even after the used catalyst is stored in air for 1 year, the catalytic activity is not decreased $\left(1780 \mu \mathrm{mol} \mathrm{g}{ }^{-1} \mathrm{~h}^{-1}\right)$ without any phase change. These observations demonstrate the excellent stability of the present catalyst.

An attempt was made to increase the surface area of the LnRuSi catalysts by vigorous milling for longer times to enhance the catalytic activity. For the LaRuSi catalyst, the surface area was increased from 1.0 to 1.4 and $1.8 \mathrm{~m}^{2} \mathrm{~g}^{-1}$ by increasing the milling time from 0.5 to 1.0 and $2.0 \mathrm{~h}$, respectively. However, the ammonia formation rates for these two samples were almost the same as that for the low surface area sample (Fig. 2a, blue symbols and Table S2 $\dagger$ ). These results suggest that the exposed $\mathrm{Ru}$ active sites did not change as the surface area increased. The La-La layer is most likely to be cleaved (Fig. S3†); therefore, longer milling times should result in an increase of the inactive $\mathrm{La}$ exposed layer rather than desired $\mathrm{Ru}$ layers. Therefore, although the surface area was increased, the exposure of Ru active sites was not significantly enhanced (shown schematically in Fig. S5a†), which resulted no significant change of the ammonia synthesis rates.

Chemical etching is one of the most powerful routes to modify the surface structure of intermetallics. ${ }^{32-35}$ For example, selective removal of Gd atoms on the surface layers was reported by etching intermetallic $\mathrm{Pt}_{5} \mathrm{Gd}$ in $\mathrm{HClO}_{4}$ solution, which led to a 5 -fold increase in the oxygen reduction reaction relative to pure $\mathrm{Pt}^{32}$ We propose that selective chemical etching with acid to remove the surface $\mathrm{Ln}$ and Si of LnRuSi could increase the exposure of $\mathrm{Ru}$ sites, which would enhance the activity for ammonia synthesis (Fig. S5b $\dagger$ ). LaRuSi was used to determine the optimal conditions for chemical etching (Table 1). The results showed that $\mathrm{HNO}_{3}$ acid did not significantly change either the activity or surface area. XRD and SEM measurements (Fig. 3) showed that there was no phase change during $\mathrm{HNO}_{3}$ treatment. This is mainly due to the oxidation ability of $\mathrm{HNO}_{3}$, which may passivate the surface by the formation of oxides. Highly concentrated $\mathrm{HCl}$ acid reacted with LaRuSi rapidly; La was completely dissolved and amorphous $\mathrm{Ru}-\mathrm{Si}$ and $\mathrm{H}_{2}$ were formed as the products (Fig. S6 and S7 $\dagger$ ). Although with a high surface area, the amorphous $\mathrm{Ru}-\mathrm{Si}$ obtained had low catalytic activity. With diluted $\mathrm{HCl}$ acid $(0.02 \mathrm{M})$, La could be partially removed, but the reaction was still very strong, whereby $\mathrm{H}_{2}$ was rapidly formed, and the catalytic activity was only slightly enhanced. The $\mathrm{H}_{2}$ formation rate was decreased significantly using $50 \% \mathrm{HCOOH}$ solution, and the ammonia formation rate for the resultant sample was increased from 1100 to $1966 \mu \mathrm{mol}$ $\mathrm{g}_{\text {cat }}{ }^{-1} \mathrm{~h}^{-1}$. These results indicate that control of the etching strength is a key factor to optimize exposure of the $\mathrm{Ru}$ sites. EDTA is a well-known chelating acid for fixing $\mathrm{Ca}^{2+}, \mathrm{Ga}^{3+}$ and $\mathrm{La}^{3+}$ ions; $^{36-38}$ therefore, EDTA-2Na solution was used for the selective etching of LaRuSi. XRD measurement shows that EDTA treated LaRuSi maintained the original phase with the minor formation of hydride, while the surface was etched (see the SEM images Fig. 3 and S9†). The concentration of the EDTA$2 \mathrm{Na}$ solution and the etching time were changed, and the activity of the EDTA-treated LaRuSi increased linearly with the surface area, unlike the sample not treated with EDTA (Fig. 2a),

Table 1 Selective chemical etching of LaRuSi with various acids

\begin{tabular}{|c|c|c|c|c|c|}
\hline Entry & Acid & $\begin{array}{l}\mathrm{pH} \text { of } \\
\text { acid solution }\end{array}$ & Etching time $(\mathrm{h})$ & $\begin{array}{l}S_{\mathrm{BET}}\left(\mathrm{m}^{2} \mathrm{~g}^{-1}\right) \text { for } \\
\text { resultant sample }\end{array}$ & $\begin{array}{l}\mathrm{NH}_{3} \text { formation rate at } 400{ }^{\circ} \mathrm{C}^{b} \\
\left(\mu \mathrm{mol} \mathrm{g}{ }^{-1} \mathrm{~h}^{-1}\right)\end{array}$ \\
\hline 1 & $1 \mathrm{M} \mathrm{HNO}_{3}$ & 0 & 3 & 2.9 & 1270 \\
\hline 3 & $0.01 \mathrm{M} \mathrm{HNO}_{3}$ & 2 & 3 & 1.7 & 1070 \\
\hline 4 & $1 \mathrm{M} \mathrm{HCl}$ & 0 & 3 & 274.0 & 50 \\
\hline 5 & $0.2 \mathrm{M} \mathrm{HCl}$ & 0.7 & 3 & 92.0 & 350 \\
\hline 8 & $10 \% \mathrm{HCOOH}$ & 1.68 & 3 & 2.8 & 1610 \\
\hline 9 & $0.1 \mathrm{M}$ EDTA-2Na & 4.92 & 3 & 1.5 & 1740 \\
\hline 10 & $0.05 \mathrm{M}$ EDTA-2Na & 4.92 & 3 & 1.7 & 2090 \\
\hline 11 & $0.01 \mathrm{M}$ EDTA-2Na & 4.94 & 3 & 3.3 & 4320 \\
\hline 12 & $0.005 \mathrm{M}$ EDTA-2Na & 4.96 & 3 & 4.1 & 5010 \\
\hline 13 & $0.001 \mathrm{M}$ EDTA-2Na & 5.02 & 3 & 4.9 & 3260 \\
\hline 18 & $0.005 \mathrm{M}$ EDTA-2Na & 4.96 & 24 & 4.1 & 5080 \\
\hline 19 & $0.005 \mathrm{M}$ EDTA-2Na & 4.96 & 30 & 4.1 & 5250 \\
\hline 20 & Without acid & - & - & 1.4 & 1100 \\
\hline
\end{tabular}

${ }^{a}$ The BET surface area was measured before ammonia synthesis. ${ }^{b}$ The activities were recorded after holding at $400{ }^{\circ} \mathrm{C}$ for $1 \mathrm{~h}$. Operation conditions: $0.1 \mathrm{~g}$ of catalyst at $400{ }^{\circ} \mathrm{C}$ and $0.1 \mathrm{MPa}$ with $\mathrm{H}_{2} / \mathrm{N}_{2}=45 / 15 \mathrm{~mL} \mathrm{~min}{ }^{-1}$ flow. 

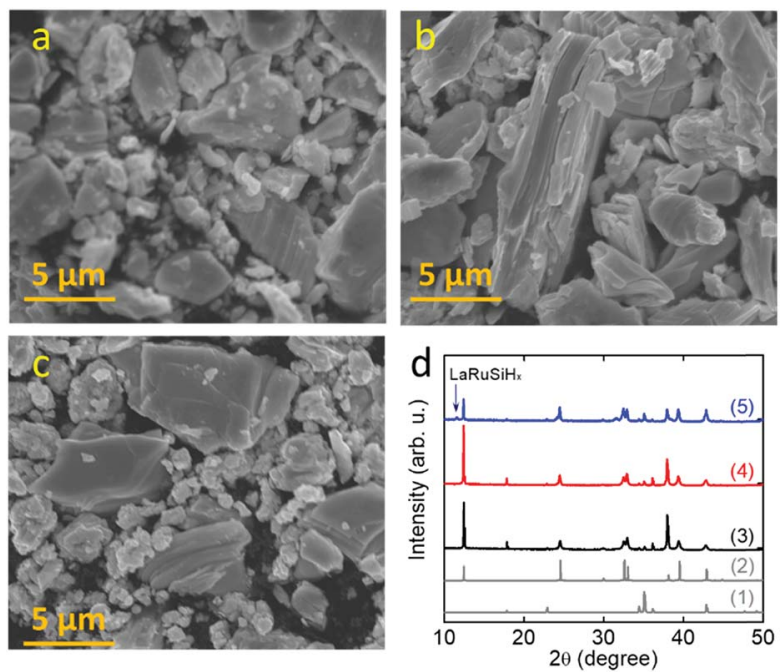

Fig. 3 SEM images of LaRuSi samples: (a) as-prepared, (b) treated in $1 \mathrm{M} \mathrm{HNO}_{3}$ acid for $5 \mathrm{~h}$, and (c) treated in $5 \mathrm{mM}$ EDTA-2Na solution for 5 h. (d) XRD patterns for: (1) $\mathrm{LaRu}_{2} \mathrm{Si}_{2}$ (simulated), (2) LaRuSi (simulated), (3) as-prepared LaRuSi, (4) LaRuSi treated in $1 \mathrm{M} \mathrm{HNO}_{3}$ acid for $5 \mathrm{~h}$, and (5) LaRuSi treated in $5 \mathrm{mM}$ EDTA-2Na solution for $5 \mathrm{~h}$.

which demonstrates that the present etching method is a promising route to enhance ammonia synthesis activity, and suggests that higher ammonia formation rates can be achieved when a finer catalyst powder is prepared. The optimized condition for etching was: $0.2 \mathrm{~g}$ LaRuSi powder with $5 \mathrm{mM}$ EDTA-2Na (10 mL) for $5 \mathrm{~h}$ (Fig. S8, $\uparrow$ etching time longer than $5 \mathrm{~h}$ did not further change the specific surface area and activity).
This treatment resulted in ammonia formation rates for LaRuSi at steady state of 3020 and $5340 \mu \mathrm{mol} \mathrm{g} \mathrm{cat}^{-1} \mathrm{~h}^{-1}$ at $340{ }^{\circ} \mathrm{C}$ and $400{ }^{\circ} \mathrm{C}$, respectively (Table 2 ), which were approximately 3 times higher than that of the original catalyst. These reaction rates were much higher than other unloaded catalysts, such as LaCoSi, ${ }^{21} \mathrm{Co}_{3} \mathrm{Mo}_{3} \mathrm{~N}^{31}$ and $\mathrm{YRu}_{2},{ }^{26}$ and even higher than that over the $\mathrm{Ru} / \mathrm{C} 12 \mathrm{~A} 7: \mathrm{e}^{-}$catalyst. $^{\mathbf{1 4}}$ The same EDTA treatment process $(0.2 \mathrm{~g}$ of catalyst placed into $10 \mathrm{~mL}$ of $5 \mathrm{mM}$ EDTA-2Na solution for $5 \mathrm{~h}$ ) was performed for the other LnRuSi catalysts and the etching of surfaces were confirmed by SEM measurement (Fig. S10-S12 $\dagger$ ). As shown in Fig. $2 \mathrm{~b}$ and Table 2, the ammonia formation rates of all the catalysts were increased 2 to 4 -fold by the EDTA treatment. The TOF values for LnRuSi were as high as ca. $0.06 \mathrm{~s}^{-1}$ at $400{ }^{\circ} \mathrm{C}$, which is 600 times higher than that for pure Ru powder and much higher than other reported unloaded catalysts and even the $\mathrm{Cs}-\mathrm{Ru} / \mathrm{MgO}$ catalyst, which demonstrates the superior performance of the present catalysts.

Fig. 2c shows the time course for $\mathrm{NH}_{3}$ formation over LaRuSi before and after treatment with EDTA. The ammonia formation rate increased initially and then became stable for the untreated sample, while it was steady for the EDTA-treated sample. This indicated that no aggregation and/or leaching occurred during ammonia synthesis. The temperature dependence was also measured for all the LnRuSi catalysts before and after EDTA treatment (Table 2). The EDTA-treated catalysts showed much higher activity than the untreated catalysts in the range examined $\left(260-400{ }^{\circ} \mathrm{C}\right)$ with similar apparent activation energies $\left(E_{\mathrm{a}}\right)$ ranging from 40 to $55 \mathrm{~kJ} \mathrm{~mol}^{-1}$ (Fig. S13†). For instance, the $E_{\mathrm{a}}$ values for LaRuSi before and after EDTA treatment were 40 and $48 \mathrm{~kJ} \mathrm{~mol}^{-1}$, respectively, which was similar to that for the

Table 2 Catalytic performance for various catalysts

\begin{tabular}{|c|c|c|c|c|c|c|c|}
\hline \multirow[b]{2}{*}{ Catalyst } & \multirow[b]{2}{*}{$S_{\mathrm{BET}}\left(\mathrm{m}^{2} \mathrm{~g}^{-1}\right)$} & \multicolumn{2}{|c|}{$r^{a}\left(\mu \mathrm{mol} \mathrm{g}{ }^{-1} \mathrm{~h}^{-1}\right)$} & \multicolumn{2}{|c|}{$\operatorname{TOF}^{b}\left(\mathrm{~s}^{-1}\right)$} & \multirow[b]{2}{*}{$E_{\mathrm{a}}\left(\mathrm{kJ} \mathrm{mol}{ }^{-1}\right)$} & \multirow[b]{2}{*}{ Ref. } \\
\hline & & $340{ }^{\circ} \mathrm{C}$ & $400{ }^{\circ} \mathrm{C}$ & $340{ }^{\circ} \mathrm{C}$ & $400{ }^{\circ} \mathrm{C}$ & & \\
\hline LaRuSi before EDTA & 1.4 & 840 & 1810 & 0.028 & 0.060 & 40 & This work \\
\hline LaRuSi after EDTA & 4.2 & 3020 & 5340 & 0.033 & 0.059 & 48 & This work \\
\hline CeRuSi before EDTA & 1.6 & 770 & 1680 & 0.022 & 0.047 & 47 & This work \\
\hline CeRuSi after EDTA & 4.0 & 2650 & 5480 & 0.030 & 0.062 & 52 & This work \\
\hline PrRuSi before EDTA & 1.5 & 560 & 1180 & 0.017 & 0.035 & 45 & This work \\
\hline PrRuSi after EDTA & 2.0 & 1010 & 2370 & 0.023 & 0.053 & 52 & This work \\
\hline NdRuSi before EDTA & 1.5 & 280 & 670 & 0.008 & 0.020 & 51 & This work \\
\hline NdRuSi after EDTA & 2.2 & 1230 & 3000 & 0.025 & 0.061 & 55 & This work \\
\hline $\mathrm{Ru}(1.2 \mathrm{wt} \%) / \mathrm{C} 12 \mathrm{~A} 7: \mathrm{e}^{-c}$ & $1-2$ & 1160 & 2760 & 0.083 & 0.197 & 49 & 9 \\
\hline $\mathrm{Ru}(1.8 \mathrm{wt} \%) / \mathrm{C} 12 \mathrm{~A} 7: \mathrm{e}^{-}$ & 1.0 & 2020 & & 0.068 & & 51 & 14 \\
\hline $\mathrm{Cs}-\mathrm{Ru}(1.0 \mathrm{wt} \%) / \mathrm{MgO}^{c}$ & 12 & & 2260 & & 0.013 & 86 & 9 \\
\hline $\mathrm{Cs}-\mathrm{Ru}(2.0 \mathrm{wt} \%) / \mathrm{MgO}$ & 12 & 3200 & & 0.009 & & 120 & 14 \\
\hline $\mathrm{Ru}$ & 3.1 & & 23 & & 0.00009 & & This work \\
\hline $\mathrm{Ru}^{d}$ & 3.1 & & 12 & & 0.00005 & & 26 \\
\hline $\mathrm{YRu}_{2}{ }^{c}$ & 0.7 & & 490 & & 0.014 & 73 & 26 \\
\hline $\mathrm{YRu}_{2}$ & 6.4 & & 3320 & & 0.011 & & 26 \\
\hline $\mathrm{Co}_{3} \mathrm{Mo}_{3} \mathrm{~N}$ & 8.5 & & 800 & & 0.0012 & 57 & 21 \\
\hline LaCoSi & 1.8 & & 1250 & & 0.031 & 42 & 21 \\
\hline $\mathrm{Fe}-\mathrm{K}_{2} \mathrm{O}-\mathrm{Al}_{2} \mathrm{O}_{3}^{e}$ & 14 & & 330 & & & 56 & 31 \\
\hline
\end{tabular}

${ }^{a}$ Operation condition: $0.1 \mathrm{~g}$ of catalyst at $0.1 \mathrm{MPa}$ with $\mathrm{H}_{2} / \mathrm{N}_{2}=45 / 15 \mathrm{~mL} \mathrm{~min}{ }^{-1}$ flow. The ammonia formation rates were measured after holding at $400{ }^{\circ} \mathrm{C}$ for 24 h. ${ }^{b} \mathrm{CO}$ is not easily adsorbed on the bulk catalysts; therefore, the estimation was conducted using the surface area $\left(S_{\mathrm{BET}}\right)$ and the covalent radii of active atoms, and the Wigner-Seitz radii as the averaged radii for the bulk compounds. ${ }^{c} 0.2 \mathrm{~g}$ of catalyst. ${ }^{d} 0.5 \mathrm{~g}$ of catalyst. ${ }^{e} 0.4 \mathrm{~g}$ of catalyst. 
electride-supported $\mathrm{Ru}$ catalysts., ${ }^{4,9,13}$ The reaction orders for LaRuSi before and after EDTA treatment were almost same (Table S6 $\dagger$ ). The positive hydrogen reaction order of around 0.6 indicates that the hydrogen poisoning effect was avoided via reversible hydrogen absorption/desorption over LaRuSi due to the intrinsic nature of the anionic electron. ${ }^{27}$ Fig. S14† shows the effect of pressure for the LaRuSi catalysts, where the ammonia formation rate increased approximately 2.6 -fold for both samples when the pressure was raised from 0.1 to $0.9 \mathrm{MPa}$.

XRD measurements were performed for the EDTA treated LnRuSi catalysts to check the stability (Fig. S15†). For all catalysts after ammonia synthesis, the $\mathrm{H}^{-}$ions, which are crucial for the formation of ammonia, ${ }^{27}$ were incorporated and $\mathrm{LnRuSiH}_{x}$ hydrides were formed as the dominant phase. Since $\mathrm{LnRu}_{2} \mathrm{Si}_{2}$ cannot incorporate $\mathrm{H}^{-}$ions, ${ }^{27}$ its phase should not be changed during ammonia synthesis, which was confirmed for the samples without EDTA treatment. However, the 122 phase increased slightly for the EDTA-treated catalysts after ammonia synthesis, which will be discussed later. Consequently, $\operatorname{LnRuSiH}_{x}$ as the actual catalyst remained stable during ammonia synthesis for EDTA-treated catalysts, i.e., EDTA treatment did not affect the robust ability of LnRuSi electrides.

ICP-AES measurement of the solution after EDTA treatment of LaRuSi was performed. As shown in Table S7, $\uparrow$ the dissolved species were predominantly $\mathrm{La}$ and $\mathrm{Si}$, while only a small amount of $\mathrm{Ru}$ was detected ( $\mathrm{ca} .3 \%$ of La), i.e., surface $\mathrm{La}$ and $\mathrm{Si}$ were removed during the EDTA etching process, so that the Ru layer emerged to the surface. The amount of La removed was slightly higher than that of $\mathrm{Si}$, which suggests the possibility for the formation of $\mathrm{LaRu}_{2} \mathrm{Si}_{2}$ at $\mathrm{Si}$-rich sites, which was confirmed by XRD measurements (Fig. S15†). XPS measurements were also conducted to evaluate the amounts and valence states of surface species. Fig. 4 shows that the intensity of the La $3 \mathrm{~d}$ and $\mathrm{Si} 2 \mathrm{~s}$ signals decreased significantly after EDTA treatment, while that of $\mathrm{Ru} 3 \mathrm{p}$ was significantly increased. The intensities of these signals changed slightly after ammonia synthesis. Fig. 4d shows the estimated ratios of surface $\mathrm{La}, \mathrm{Ru}$ and $\mathrm{Si}$. The Ru ratio increased from 0.15 to 0.54 after EDTA treatment, and decreased slightly to 0.46 after ammonia synthesis, probably due to the reconstruction process. The La to Si ratio was almost constant for all three samples, which indicates that the surface La and Si layers were simultaneously removed during EDTA treatment, as supported by the ICP-AES results. Both the ICP-AES and XPS results revealed that the amount of exposed Ru sites on the surface was increased after EDTA treatment, which was the key reason for enhancement of the catalytic activity. On the other hand, the valence state of $\mathrm{Ru}$ was initially negative (460.6 eV present, and $461.4 \mathrm{eV}$ for $\mathrm{Ru}$ metal); it became positive after EDTA treatment ( $461.9 \mathrm{eV})$ due to the partially oxidation of exposed $\mathrm{Ru}$ on the surface, and then returned to negative $(460.8 \mathrm{eV})$ with the reduction of hydrogen during ammonia synthesis. This indicates that during ammonia synthesis, the exposed Ru was still in a negatively charged state for the EDTA-treated catalysts.

Most of the catalytic properties of LaRuSi, including the activation energy, reaction orders and pressure effect, remain unchanged before and after EDTA treatment, which suggests that the active sites for both samples are layered $\mathrm{Ru}$ in the
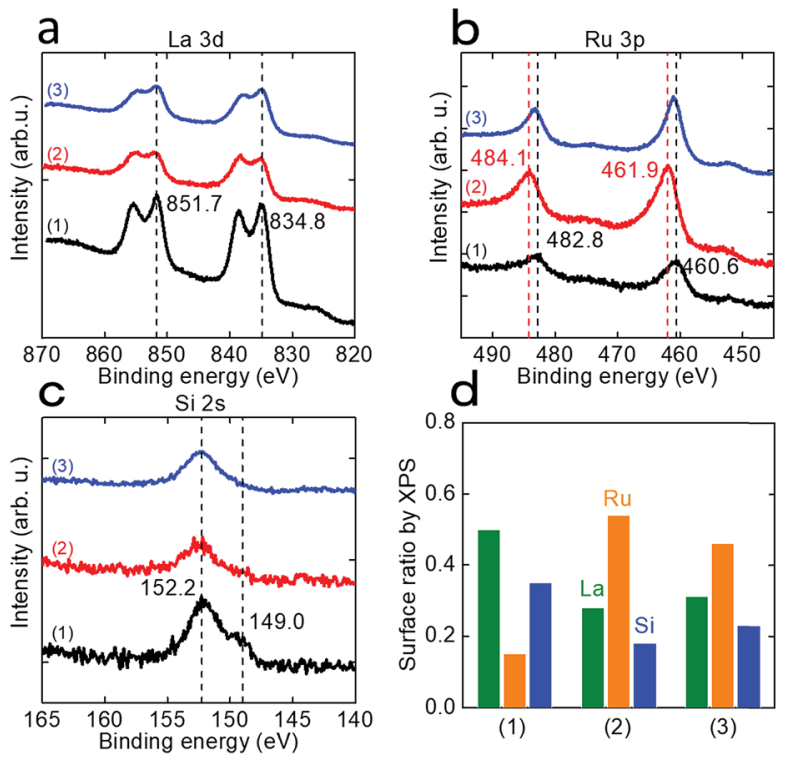

Fig. 4 XPS (a) La 3d, (b) Ru 3p and (c) Si 2s spectra for various LaRuSi catalysts: (1) without EDTA treatment, and with EDTA treatment (2) before and (3) after ammonia synthesis at $400{ }^{\circ} \mathrm{C}$ for $80 \mathrm{~h}$. (d) Surface ratios of $\mathrm{La}, \mathrm{Ru}$ and $\mathrm{Si}$ obtained from the XPS peak area.

negative charge state; however, the possibility for the formation of $\mathrm{Ru}$ nanoparticles via aggregation on the surface during reaction cannot be excluded. Therefore, HAADF-STEM measurements were performed to determine whether $\mathrm{Ru}$ nanoparticles were formed on EDTA-treated LaRuSi. The homogeneous lattice fringes were present in both bright and dark areas (Fig. 5), which demonstrates that there were no Ru nanoparticles on the surface. This was further supported by the FFT pictures in Fig. 5 and the selected area electron diffraction pattern in Fig. S16: $\dagger$ the tetragonal structure corresponding to LaRuSi lattice was clearly observed, while the hexagonal structure that corresponds to Ru metal was not observed. In addition, no $\mathrm{Ru}$ peaks were evident in the powder XRD measurements (Fig. S15†). Therefore, it was concluded that there were no Ru particles on the EDTA-treated LaRuSi surface.

We have recently reported that the LaRuSi electride exhibited good activity for ammonia synthesis due to its electride character; negatively charged $\mathrm{Ru}$ together with lattice $\mathrm{H}^{-}$ions, which can reversibly exchange with anionic electrons, are the key factors in the promotion of ammonia formation. ${ }^{27} \mathrm{~A}$ large difference in the activation energy for ammonia formation $\left(40 \mathrm{~kJ} \mathrm{~mol}^{-1}\right)$ and $\mathrm{N}_{2}$ isotope exchange reaction $\left(157 \mathrm{~kJ} \mathrm{~mol}^{-1}\right)$ indicated the strong adsorption of $\mathrm{N}_{2}$ or $\mathrm{N}$ atoms on the LaRuSi surface, so that $\mathrm{N}_{2}$ would be activated through the hot-atom mechanism suggested for LaCoSi. ${ }^{21}$ The heat released from adsorption leads to the simultaneous desorption of $\mathrm{H}$ from lattice $\mathrm{H}^{-}$, which immediately combines with adsorbed $\mathrm{N}$ to form $\mathrm{NH}_{x}$. The $\mathrm{Ru}-\mathrm{N}$ bond is thus weakened through the hydrogenation process, and ammonia is finally formed and desorbed. However, how planar Ru in LnRuSi acts to activate $\mathrm{N}_{2}$ has not been discussed previously. It is well-accepted that terrace $\mathrm{Ru}$ atoms are not active for ammonia synthesis because 

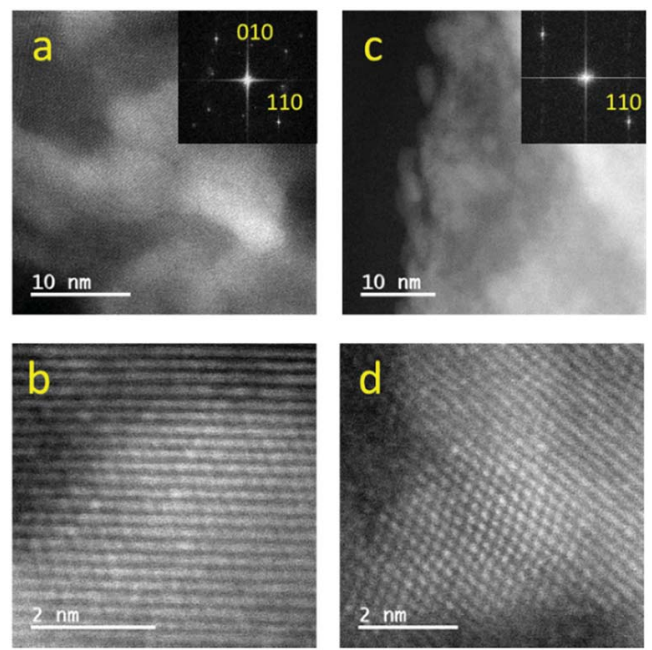

Fig. 5 HAADF-STEM images of EDTA-treated LaRuSi catalyst. (a and b) Before and ( $c$ and d) after ammonia synthesis. Insets in (a) and (c) show the fast Fourier transform (FFT) for the images, which indicate that the catalyst is a tetragonal structure.

both experiments and DFT calculations showed that the apparent activation energy for $\mathrm{N}_{2}$ dissociation at terrace sites of the $\mathrm{Ru}$ (0001) face was as high as 1.8-1.9 eV. Considering the large $\mathrm{Ru}-\mathrm{Ru}$ distance in LnRuSi (ca. $0.30 \mathrm{~nm}$, Table S8†), which differs from $\mathrm{Ru}$ metal or $\mathrm{YRu}_{2}(c a .0 .26 \mathrm{~nm})$, together with the layered geometric configuration, $\mathrm{N}_{2}$ activation over LnRuSi should be different from that over conventional $\mathrm{Ru}$ catalysts.

Here DFT calculations were performed to investigate how the $\mathrm{N}_{2}$ was adsorbed and activated on the LaRuSi(001)-Ru surface; the reaction path for $\mathrm{N}_{2}$ dissociation and the adsorption states are shown in Fig. 6 and S17-S19, $\dagger$ respectively. The most stable adsorption configuration of $\mathrm{N}_{2}$ on LaRuSi(001)-Ru is where a $\mathrm{N}_{2}$ molecule is adsorbed parallel on the hollow site of La and bonded with four surface $\mathrm{Ru}$ atoms, and $\mathrm{La}$ is beneath the surface $\mathrm{Ru}$ layer and centered within a square of $\mathrm{Ru}$ atoms (Fig. S17a $\dagger$ ). The deformation charge density for this adsorption state (Fig. S19a†) clearly showed that electrons are transferred

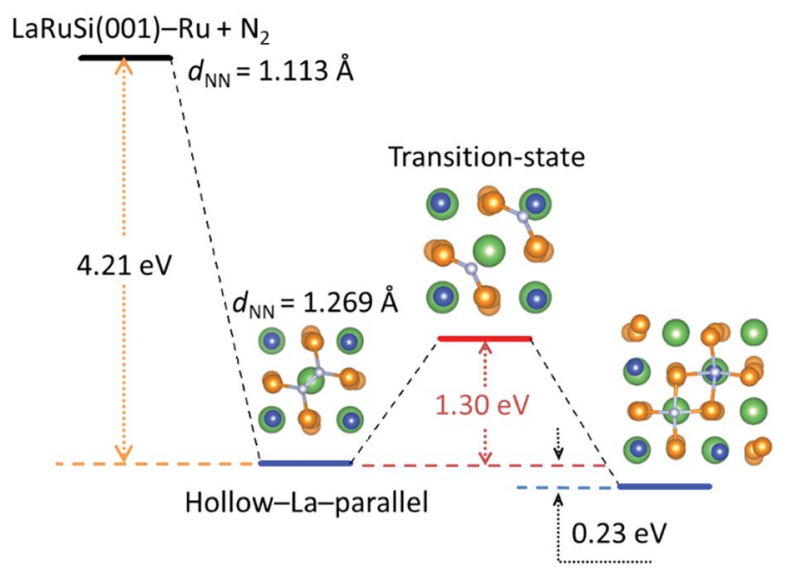

Fig. $6 \mathrm{~N}_{2}$ activation pathways on the LaRuSi(001)-Ru surface by DFT calculations. from $\mathrm{Ru}$ to $\mathrm{N}_{2}$, which weakens the $\mathrm{N} \equiv \mathrm{N}$ triple bond with an elongated bond length (from $0.111 \mathrm{~nm}$ to $0.127 \mathrm{~nm}$ ). As a result, the negatively charged nitrogen has a strong coulombic attraction with the positively charged lanthanum atom, which leads to a larger adsorption energy of $-4.21 \mathrm{eV}$. The $\mathrm{N}_{2}$ dissociation barrier is $1.30 \mathrm{eV}$, and two dissociated $\mathrm{N}$ atoms locate at the hollow sites of La and Si with an adsorption energy of $-4.44 \mathrm{eV}$ (Fig. S18a $\dagger$ ). The strong exothermic adsorption of $\mathrm{N}_{2}$ and the relatively low dissociation barrier indicate that the adsorbed $\mathrm{N}_{2}$ can be easily dissociated into $\mathrm{N}$ atoms without further addition of energy. ${ }^{21}$ In this model, all $\mathrm{Ru}$ atoms on the surface are active for ammonia synthesis. This is quite different from that of the conventional Ru catalyst. For instance, $\mathrm{N}_{2}$ activation only occurs at $\mathrm{B}_{5}$ sites in the conventional $\mathrm{Ru}$ catalyst, and the adsorption energies for $\mathrm{N}_{2}$ and $2 \mathrm{~N}$ are respectively -0.7 and $-0.8 \mathrm{eV},{ }^{17,18}$ which are much lower than that on the LaRuSi surface. In the conventional $\mathrm{Ru}$ catalyst, $\mathrm{N}_{2}$ is adsorbed perpendicular on the step site and the overall dissociation barrier is $0.4 \mathrm{eV}$ with the dissociated $\mathrm{N}$ adsorbed at the 3 -fold hcp site. ${ }^{19}$ These differences clearly demonstrate that layered $\mathrm{Ru}$ in LnRuSi is independent from $B_{5}$ site active centers for ammonia synthesis. Further calculations and related studies to clarify the detailed reaction mechanism are in progress.

\section{Conclusions}

In summary, we have reported a $\mathrm{B}_{5}$-site-independent $\mathrm{Ru}$ catalyst, the LnRuSi electride, which exhibits good performance for ammonia synthesis. With respect to their robust durability toward acids, surface Ln and Si are removed while more Ru sites emerge by selective etching using EDTA-2Na acid, which results in a 2- to 4-fold increase in the activity compared to that of the original samples. The estimated TOFs for the LnRuSi catalysts under mild conditions $\left(0.1 \mathrm{MPa}, 400^{\circ} \mathrm{C}\right)$ were approximately 0.06 $\mathrm{s}^{-1}$, which is 600 times higher than that of $\mathrm{Ru}$ powder. DFT calculations revealed that the specific LnRuSi structure stabilized $\mathrm{N}_{2}$ adsorption with a strong exothermic effect, which decreased the apparent activation energy for $\mathrm{N}_{2}$ dissociation. Therefore, $\mathrm{N}_{2}$ activation is much easier on the Ru plane of LnRuSi than that on conventional $\mathrm{Ru}$ catalysts. We propose that the present air- and acid-durable LnRuSi electride catalysts are applicable to catalytic reactions in water/acid atmospheres, in which conventional electrides do not function well. The present EDTA etching method would also be useful to enhance the activities of other noble metal-containing intermetallic catalyst systems.

\section{Conflicts of interest}

There are no conflicts to declare.

\section{Acknowledgements}

This work was supported by the Japan Society for the Promotion of Science (JSPS) through a Grant-in-Aid for Scientific Research (S), No. 17H06153. Y. L. is supported by the JSPS fellowship for young scientists (No. 18J00745). X. W. is supported by Ministry of Science and Technology of the People's Republic of China 
(MOST), No. 2018YFA0208603, No. 2016YFA0200602, National Natural Science Foundation of China (NSFC), No. 21573204, Anhui Initiative in Quantum Information Technologies (No. AHY090400), the Fundamental Research Funds for the Central Universities, National Program for Support of Top-Notch Young Professional, and External Cooperation Program of BIC CAS (211134KYSB20130017). We would like to express our appreciation to Prof. Michikazu Hara for use of the XPS instrument.

\section{Notes and references}

1 K. Aika, H. Hori and A. Ozaki, J. Catal., 1972, 27, 424-431.

2 Z. Song, T. H. Cai, J. C. Hanson, J. A. Rodriguez and J. Hrbek, J. Am. Chem. Soc., 2004, 126, 8576-8584.

3 N. Saadatjou, A. Jafari and S. Sahebdelfar, Chem. Eng. Commun., 2015, 202, 420-448.

4 J. Z. Wu, Y. T. Gong, T. Inoshita, D. C. Fredrickson, J. J. Wang, Y. F. Lu, M. Kitano and H. Hosono, Adv. Mater., 2017, 29, 1700924.

5 K. Aika, K. Shimazaki, Y. Hattori, A. Ohya, S. Ohshima, K. Shirota and A. Ozaki, J. Catal., 1985, 92, 296-304.

$6 \mathrm{H}$. Bielawa, O. Hinrichsen, A. Birkner and M. Muhler, Angew. Chem., Int. Ed., 2001, 40, 1061-1063.

7 J. J. Mortensen, B. Hammer and J. K. Nørskov, Phys. Rev. Lett., 1998, 80, 4333-4336.

8 K. Aika, Catal. Today, 2017, 286, 14-20.

9 M. Kitano, Y. Inoue, Y. Yamazaki, F. Hayashi, S. Kanbara, S. Matsuishi, T. Yokoyama, S. W. Kim, M. Hara and H. Hosono, Nat. Chem., 2012, 4, 934-940.

10 Y. Inoue, M. Kitano, S. W. Kim, T. Yokoyama, M. Hara and H. Hosono, ACS Catal., 2014, 4, 674-680.

11 S. Kanbara, M. Kitano, Y. Inoue, T. Yokoyama, M. Hara and H. Hosono, J. Am. Chem. Soc., 2015, 137, 14517-14524.

12 M. Kitano, S. Kanbara, Y. Inoue, N. Kuganathan, P. V. Sushko, T. Yokoyama, M. Hara and H. Hosono, Nat. Commun., 2015, 6, 6731.

13 Y. F. Lu, J. Li, T. Tada, Y. Toda, S. Ueda, T. Yokoyama, M. Kitano and H. Hosono, J. Am. Chem. Soc., 2016, 138, 3970-3973.

14 M. Kitano, Y. Inoue, H. Ishikawa, K. Yamagata, T. Nakao, T. Tada, S. Matsuishi, T. Yokoyama, M. Hara and H. Hosono, Chem. Sci., 2016, 7, 4036-4043.

15 C. J. H. Jacobsen, S. Dahl, P. L. Hansen, E. Törnqvist, L. Jensen, H. Topsøe, D. V. Prip, P. B. Møenshaug and I. Chorkendorff, J. Mol. Catal. A: Chem., 2000, 163, 19-26.

16 W. Raróg-Pilecka, E. Miśkiewicz, D. Szmigiel and Z. Kowalczyk, J. Catal., 2005, 231, 11-19.

17 K. Honkala, A. Hellman, I. N. Remediakis, A. Logadottir, A. Carlsson, S. Dahl, C. H. Christensen and J. K. Nørskov, Science, 2005, 307, 555-558.

18 A. Lógadottir and J. K. Nørskov, J. Catal., 2003, 220, 273-279.
19 S. Dahl, A. Logadottir, R. C. Egeberg, J. H. Larsen, I. Chorkendorff, E. Törnqvist and J. K. Nørskov, Phys. Rev. Lett., 1999, 83, 1814-1817.

20 L. Diekhöner, H. Mortensen, A. Baurichter, A. C. Luntz and B. Hammer, Phys. Rev. Lett., 2000, 84, 4906-4909.

21 Y. T. Gong, J. Z. Wu, M. Kitano, J. J. Wang, T. N. Ye, J. Li, Y. Kobayashi, K. Kishida, H. Abe, Y. Niwa, H. S. Yang, T. Tada and H. Hosono, Nat. Catal., 2018, 1, 178-185.

22 T. N. Ye, Y. F. Lu, J. Li, T. Nakao, H. S. Yang, T. Tada, M. Kitano and H. Hosono, J. Am. Chem. Soc., 2017, 139, 17089-17097.

23 M. Armbrüster, K. Kovnir, M. Friedrich, D. Teschner, G. Wowsnick, M. Hahne, P. Gille, L. Szentmiklósi, M. Feuerbacher, M. Heggen, F. Girgsdies, D. Rosenthal, R. Schlögl and Y. Grin, Nat. Mater., 2012, 11, 690-693.

24 M. Armbrüster, R. Schlögl and Y. Grin, Sci. Technol. Adv. Mater., 2014, 15, 034803.

25 L. Piccolo, L. Kibis, M. C. de Weerd, E. Gaudry, J. Ledieu and V. Fournée, ChemCatChem, 2017, 9, 2292-2296.

26 T. Ogawa, Y. Kobayashi, H. Mizoguchi, M. Kitano, H. Abe, T. Tada, Y. Toda, Y. Niwa and H. Hosono, J. Phys. Chem. C, 2018, 122, 10468-10475.

27 J. Z. Wu, J. Li, Y. T. Gong, M. Kitano, T. Inoshita and H. Hosono, Angew. Chem., Int. Ed., 2019, 58, 825-829.

28 A. Ellaboudy, J. L. Dye and P. B. Smith, J. Am. Chem. Soc., 1983, 105, 6490-6491.

29 R. H. Huang, M. K. Faber, K. J. Moeggenborg, D. L. Ward and J. L. Dye, Nature, 1988, 331, 599-601.

30 S. Matsuishi, Y. Toda, M. Miyakawa, K. Hayashi, T. Kamiya, M. Hirano, I. Tanaka and H. Hosono, Science, 2003, 301, 626-629.

31 R. Kojima and K. Aika, Appl. Catal., A, 2001, 218, 121-128.

32 M. Escudero-Escribano, A. Verdaguer-Casadevall, P. Malacrida, U. Grønbjerg, B. P. Knudsen, A. K. Jepsen, J. Rossmeisl, I. E. L. Stephens and I. Chorkendorff, J. Am. Chem. Soc., 2012, 134, 16476-16479.

33 L. Wang and Y. Yamauchi, J. Am. Chem. Soc., 2013, 135, 16762-16765.

34 W. Zhang, Y. Y. Zhao, V. Malgras, Q. M. Ji, D. M. Jiang, R. J. Qi, K. Ariga, Y. Yamauchi, J. Liu, J. S. Jiang and M. Hu, Angew. Chem., Int. Ed., 2016, 55, 8228-8234.

35 Y. C. Pi, Q. Shao, X. Zhu and X. Q. Huang, ACS Nano, 2018, 12, 7371-7379.

36 G. A. Elgavish and J. Reuben, J. Am. Chem. Soc., 1976, 98, 4755-4759.

37 S. Harada, Y. Funaki and T. Yasunaga, J. Am. Chem. Soc., 1980, 102, 136-139.

38 M. R. Zhang, F. Hou, Z. G. Wang, S. H. Zhang and G. B. Pan, Appl. Surf. Sci., 2017, 410, 332-335. 